\title{
Expression of the Alpha8 Integrin Chain Facilitates Phagocytosis by Renal Mesangial Cells
}

\author{
Ines Marek ${ }^{\mathrm{a}} \quad$ Robert Becker $^{\mathrm{b}} \quad$ Fabian B. Fahlbusch ${ }^{\mathrm{a}} \quad$ Carlos Menendez-Castro $^{\mathrm{a}}$ \\ Wolfgang Rascher ${ }^{\mathrm{a}} \quad$ Christoph Daniel $^{\mathrm{b}} \quad$ Gudrun Volkert ${ }^{\mathrm{a}} \quad$ Andrea Hartner $^{\mathrm{a}}$ \\ a Department of Pediatrics and Adolescent Medicine, 'Institute of Nephropathology, University Hospital \\ of Erlangen, Erlangen, Germany
}

\section{Key Words}

Alpha8 integrin - Itga8 - Phagocytosis - Mesangial cells • Extracellular matrix resolution • Cytoskeleton • Glomerulonephritis

\begin{abstract}
Background/Aims: Healing of mesangioproliferative glomerulonephritis involves degradation of excess extracellular matrix, resolution of hypercellularity by apoptosis and phagocytosis of apoptotic cells. Integrin receptors participate in the regulation of phagocytosis. In mice deficient for alpha8 integrin (Itga8-/-) healing of glomerulonephritis is delayed. As Itga8 is abundant in mesangial cells (MC) which are non-professional phagocytes, we hypothesized that Itga8 facilitates phagocytosis of apoptotic cells and matrix components by MC. Methods: MC were isolated from wild type (WT) and Itga8-/- mice. Latex beads were coated with matrix components. Apoptosis was induced by cisplatin in macrophages and in DiI-stained MC. After coincubation of latex beads or apoptotic cells with MC, the phagocytosis rate was detected in WT and Itga8-/- MC via fluorescence microscopy and FACS analysis. Results: Itga8-/- MC showed reduced phagocytosis of matrix-coated beads and apoptotic cells compared to WT MC. Reduction of stress fibers was observed in Itga8-/- compared to WT MC. Inhibition of cytoskeletal reorganization by inhibition of Rac1 or ROCK during phagocytosis significantly decreased the rate of phagocytosis by WT MC but not by Itga8-/- MC. Conclusion: The expression of Itga8 facilitates phagocytosis in MC, likely mediated by Itga8-cytoskeleton interactions. An impairment of MC phagocytosis might thus contribute to a delayed glomerular regeneration in Itga8-/- mice.
\end{abstract}




\section{Cellular Physiology Cell Physiol Biochem 2018;45:2161-2173 \begin{tabular}{ll|l} 
and Biochemistry Published onlıne: March 15, 2018 & $\begin{array}{l}\text { C) } 2018 \text { The Author(s). Published by S. Karger AG, Basel } \\
\text { www.karger.com/cpb }\end{array}$ \\
\hline
\end{tabular}

\section{Introduction}

Glomerulonephritis is characterized by invasion of inflammatory cells, cell proliferation and extracellular matrix expansion. In acute forms of glomerulonephritis, regenerative mechanisms contribute to the resolution of glomerular inflammation, hypercellularity and fibrosis, thereby restoring the balance between proliferation, matrix deposition, apoptosis, phagocytosis of inflammatory cells, surplus mesangial cells and extracellular matrix components [1]. The latter involves the engulfment of large particles through formation of vesicles called phagosomes. Phagocytosis is not limited to "professional" phagocytes such as macrophages, but also performed by "non-professional" phagocytes such as epithelial, endothelial, neuronal and mesenchymal cells [2]. Phagocytosis by non-professional phagocytes is an important mechanism to maintain tissue homeostasis which eliminates apoptotic cells and matrix components from tissue [3,4]. In experimental glomerulonephritis, phagocytosis of apoptotic mesangial cells by neighbouring healthy mesangial cells leads to the resolution of hypercellularity [5] and thereby contributes to restoring the integrity of the glomerular tuft.

A wide variety of receptor-ligand interactions and signaling pathways has been implicated in phagocytosis, summarized in [6-8]. Recognition and binding of apoptotic cells commonly lead to the intracellular activation of Rho-GTPases and subsequent remodeling of the actin cytoskeleton [2]. Signaling via Rac1 is described to be active in the phagocytic cup [9], and in FCyR-dependent phagocytosis, whereas signaling via RhoA is essential for $\alpha M \beta 2$ integrin-mediated phagocytosis [10]. Integrins can promote phagocytosis in different cell types, such as epithelial, endothelial and mesenchymal cells dependent on their lineage $[2$, 11]. In immune cells, e.g. $\alpha \mathrm{M} \beta 2, \alpha \mathrm{V} \beta 3, \alpha \mathrm{V} \beta 5$ and $\alpha 6 \beta 1$ integrins are described as mediators of phagocytosis (summarized in [2]). In macrophages, $\alpha M \beta 5$ integrin is described as a prophagocytotic integrin which activates RhoA. RhoA activation results in ROCK-mediated myosin II phosphorylation which is necessary for F-actin turnover to seal engulfed particles [12]. $\alpha \mathrm{V} \beta 5$ integrin is able to bind and internalize apoptotic cells via Rac1 activation $[13,14]$. In trabecular meshwork cells, $\alpha \mathrm{V} \beta 5$ integrin mediates phagocytosis via FAK activation, while $\alpha V \beta 3$ reduces phagocytotic activity in these cells [15]. In contrast, $\alpha \mathrm{V} \beta 3$ serves to internalize apoptotic neutrophils in macrophages [13]. In human breast cancer cells, $\alpha 3 \beta 1$ mediates phagocytosis of extracellular matrix [16]. In microglia, $\alpha 6 \beta 1$ integrin is described to be a component of the complex that can internalize fibrillary $\beta$-amyloids [17]. Fibroblasts are able to phagocyte collagens via $\alpha 2 \beta 1$ integrin after integrin clustering and Rac1 activated F-actin reassembly $[18,19]$. In mesangial cells, $\alpha \mathrm{V} \beta 3$ seems to be involved in phagocytosis as internalization of apoptotic cells by mesangial cells was found to be reduced following inhibition of the $\alpha \mathrm{V} \beta 3 /$ thrombospondin/CD36 pathway [20,21].

Alpha8 integrin (Itga8) is an RGD binding integrin which is expressed on mesangial cells and regulates their biological properties including adhesion, proliferation, migration and apoptosis by interacting with extracellular ligands such as fibronectin, vitronectin or osteopontin [22, 23]. Its role for phagocytosis is not yet known. However, previous in vivo studies in Itga8-deficient mice indicated a contribution of Itga8 to the resolution of glomerular injury after acute mesangioproliferative glomerulonephritis [24]. Healing of glomerular damage was considerably delayed in Itga8-deficient mice [24]. Thus, we hypothesized that Itga8 might contribute to phagocytosis of apoptotic mesangial cells, inflammatory cells and degraded extracellular matrix components in glomeruli after an inflammatory insult. It was further assumed that in mesangial cells with a deficiency for Itga 8 phagocytosis might be impaired. We performed in vitro studies using wild type and Itga8-deficient mesangial cells to analyze the contribution of Itga 8 to phagocytosis of apoptotic cells and extracellular matrix components. 


\section{Cellular Physiology Cell Physiol Biochem 2018;45:2161-2173 \begin{tabular}{l|l} 
and Biochemistry & DOI: 10.1159/000488160 \\
Published 2018 The Author(s). Published by S. Karger AG, Basel
\end{tabular} \\ Marek et al.: Mesangial Itga8 and Phagocytosis}

\section{Materials and Methods}

\section{Cell culture}

Mesangial cells (MC) were isolated from kidneys of healthy wild type (WT) or Itga8-deficient (Itga8/-) mice (obtained from U. Müller, Scripps Institute, LaJolla, USA) by the sieving method and characterized as described before $[23,25]$. Rat MC were isolated from Sprague-Dawley rats as described in [26]. MC were grown in Dulbecco's modified Eagle's Medium (DMEM with L-Glutamine; PAA Laboratories GmbH, Pasching, Austria) containing 10\% FCS, 1\% penicillin-streptomycin, $0.1 \%$ insulin (Sigma, Deisenhofen, Germany) in a $95 \%$ air $-5 \% \mathrm{CO}_{2}$ humidified atmosphere at $37^{\circ} \mathrm{C}$. MC were used for experiments in passages $5-18$. A stably GFP-transfected murine macrophage cell line (GFP-RAW) (gift from B. Wielockx and J. Kalucka, Dresden, Germany [27]) was cultivated in DMEM with L-Glutamin containing 10\% FCS, 1\% penicillin-streptomycin in a $95 \%$ air $-5 \% \mathrm{CO}_{2}$ humidified atmosphere at $37^{\circ} \mathrm{C}$. A stably Itga8 overexpressing $\mathrm{HEK}$ cell line (Itga8+/+ HEK) (described in [23]) was cultivated in DMEM with L-Glutamin containing 10\% FCS, 1\% penicillin-

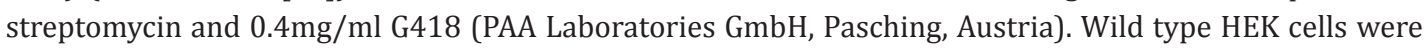
used as a control (co HEK).

\section{Generation of apoptotic cells}

Apoptosis was induced in vitro by incubation of either GFP-RAW cells or vybrant DiI (Molecular Probes Life Technologies, Eugene, OR, USA) stained MC with $50 \mu \mathrm{M}$ cisplatin (cis-diamineplatinum (II) dichloride from Sigma-Aldrich, Munich, Germany) for 24 hours at $37^{\circ} \mathrm{C}$ similar as described before [24]. For vybrant DiI dye staining, MC were seeded in culture dishes and were allowed to adhere overnight. Then, vybrant DiI dye was added $\left(5 \mu \mathrm{l} / \mathrm{ml}\right.$ DMEM) for $10 \mathrm{~min}$ at $37^{\circ} \mathrm{C}$. Apoptosis was evaluated as described in [24]. Hoechst staining was used to analyze apoptosis via counting of chromatin-condensed cells. Trypan blue exclusion was used to determine viability (in average $80 \%$ ).

\section{Phagocytosis of apoptotic cells}

Phagocytosis was analyzed by performing co-culture of apoptotic cells (GFP-RAW, MC) with nonapoptotic MC at different time points. Apoptotic GFP-RAW macrophages and native, adherent MC were coincubated at a ratio of 10:1 (apoptotic RAW to native MC) for 2, 4, 6 and 24 hours. For phagocytosis of apoptotic MC, apoptotic Dil stained MC and native, unstained adherent MC were co-incubated at a ratio of 2.5:1 (apoptotic to native MC) for 4 and 24 hours. The phagocytosis rate of apoptotic cells was compared in WT and Itga8-/- MC via fluorescence microscopy or FACS analysis.

\section{Phagocytosis of matrix-coated beads}

A latex bead model [28-30] was employed to study phagocytosis of extracellular matrix components $(2 \mu \mathrm{m}$, latex, carboxylate-modified polystyrene, yellow-green fluorescent beads from Sigma-Aldrich) in MC. Latex beads were coated with the Itga 8 ligand fibronectin $(10 \mu \mathrm{g} / \mathrm{ml}$ in PBS) (Sigma-Aldrich), collagen type $\mathrm{I}$, which is not a ligand for Itga8 $(0.3 \mu \mathrm{g} / \mathrm{ml}$ in PBS) (Collaborative Biomedical Products, Bedford, MA, USA), or mouse serum (gift from C. Warnecke, Erlangen, Germany) at $37^{\circ} \mathrm{C}$ for 1 hour. Mouse serum was used as an unspecific coating control (similar to [31]). MC (WT: 10, 000 cells/well, Itga8-/- 15, 000 cells/well) were seeded on glass 8 -well chamber slides coated with fibronectin $(10 \mu \mathrm{g} / \mathrm{ml})$. Cells were allowed to attach overnight. MC were layered with coated beads in a ratio of 1:50 (cells to beads). The optimal matrix coating concentration and the optimal incubation time for phagocytosis was assessed in pilot studies, similar as in [29, 30, 32-35] (see Fig. 1). After 24 hours of incubation at $37^{\circ} \mathrm{C}$, cells were washed with saline and fixed in 4\% paraformaldehyde. Nuclei were stained with DaPi (1:2000; Sigma-Aldrich) and actin filaments with rhodamine/phalloidin (5mM; Molecular Probes, Eugene, OR, USA), as described before [22]. The phagocytosis rate of latex beads was assessed via fluorescence microscopy.

For analysis of phagocytosis of fibronectin-coated latex beads in Itga8 overexpressing cells, Itga8+/+ and co HEK cells $(30,000$ cells/well) were seeded on glass 8 -well chamber slides coated with fibronectin $(10 \mu \mathrm{g} / \mathrm{ml})$. The next day, HEK cells were layered with fibronectin-coated $(10 \mu \mathrm{g} / \mathrm{ml})$ beads in the ratio of 1:50 (cells to beads). For HEK cell experiments, latex beads (carboxylate-modified polystyrene, yellowgreen fluorescent beads from Sigma-Aldrich) with a size of $1 \mu \mathrm{m}$ were chosen as described in [36. 37] and phagocytosis was analyzed as described above for MC after 3 and 24 hours by fluorescence microscopy. 


\section{Cellular Physiology Cell Physiol Biochem 2018;45:2161-2173 \begin{tabular}{l|l|l} 
DOI: 10.1159/000488160 & O 2018 The Author(s). Published by S. Karger AG, Basel \\
www.karger.com/cpb
\end{tabular} \\ Marek et al.: Mesangial Itga8 and Phagocytosis}

Fig. 1. Testing conditions for phagocytosis of beads. A, Comparison of the phagocytosis of serum-coated beads by $\alpha 8$ integrin-deficient (Itga8-/-) and wild type (WT) mesangial cells (MC) after 3 and 24 hours $(3 \mathrm{~h}, 24 \mathrm{~h})$, cell-to-bead ratio $=1: 50$, $\mathrm{N}=4,{ }^{*}=\mathrm{p}<0.0524 \mathrm{~h}$ versus $3 \mathrm{~h}$. B, Comparison of the phagocytosis of matrix-coated beads, using different coating concentrations, by Itga8-/- and wild type MC after 24 hours, cell-to-bead ratio $=1: 50$, $\mathrm{FN}=$ Fibronectin, $\mathrm{COL}=$ Collagen $\mathrm{I}, \mathrm{N}=3$, $*=p<0.05$ Itga8-/- versus wild type MC. $\mathrm{C}$, Phagocytosis of serum-coated beads in Itga8-/- and wild type MC in dependence of the cell-to-bead ratio (1:5 versus 1:50) after 24 hours, $\mathrm{N}=3,{ }^{*}=\mathrm{p}<0.051: 5$ versus 1:50 cell-to-bead ratio. $D$, Inhibition of the
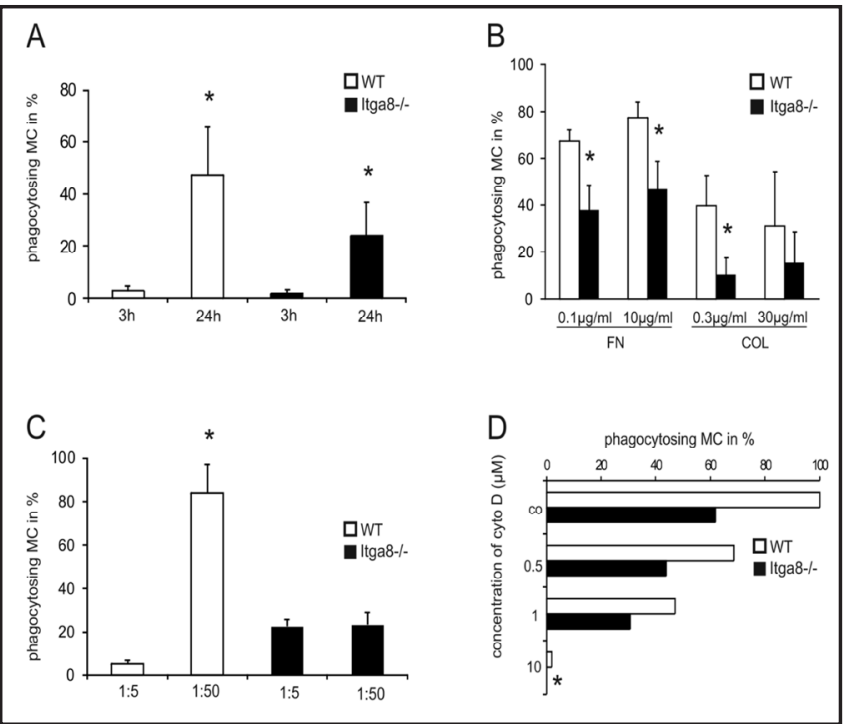
ingestion of serum-coated beads by cytochalasin D (cyto D) in Itga8-/- and wild type MC in dependence of the cyto D concentration after 24 hours. Results are representative for three similar experiments. co=solvent control. * = no phagocytosis detected, all Itga8-/- MC dead. Phagocytosis in untreated wild type MC is set to $100 \%$.

\section{Flow cytometry}

For FACS analysis (Canto II, BD Biosciences, Heidelberg, Germany), $\quad$ FITC-channel (530nm wave length) was used to detect the phagocytosis of apoptotic GFP-RAW cells. PEchannel (585nm wave length) was used to detect phagocytosis of apoptotic red fluorescent DiI stained MC. FSC (forward scatter channel) was used to quantify the size and SSC (side scatter channel) to detect the granularity of the cells (see Fig. 2).

\section{Fluorescence microscopy}

Internalization of apoptotic GFP-RAW cells by MC was analyzed after co-incubation for 2, 4, 6 and 24 hours. Cells were fixed in $4 \%$ paraformaldehyde before microscopic evaluation (NIKON Eclipse 80i, Düsseldorf) in bright field and fluorescence microscopy. For phagocytosis of apoptotic Dil stained MC by MC, cells were fixed after 4 and 24 hours and evaluated in the same manner. Bead internalization was confirmed with fluorescence microscopy (NIKON Eclipse 80i) and inverted microscopy with z-stack images (Keyence, Neu-Isenburg, Germany), (see Fig. 3). The quantitative analysis of the phagocytosis rate was
B

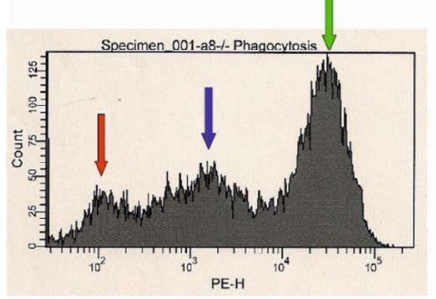

C

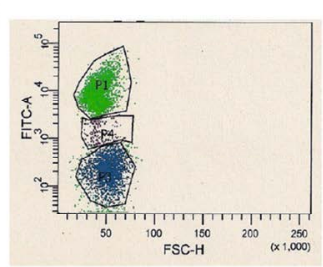

D

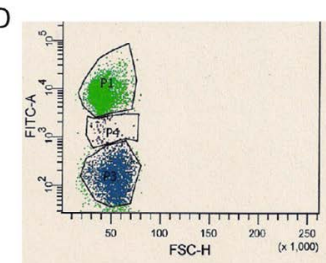

Fig. 2. FACS analysis of phagocytosis. A, B, Phagocytosis of apoptotic DiI-stained $\alpha 8$ integrin-deficient (Itga8-/-) mesangial cells (MC) after 4 hours. Apoptotic, DiI-stained MC correspond to green dots in (A), green arrow points to DiI-stained apoptotic MC in (B). Native, not phagocytosing $\mathrm{MC}$ are shown by red dots (A) and red arrow (B). Phagocytosing MC correspond to blue dots (A), blue arrow points to phagocytosing MC (B). C, D, Phagocytosis of apoptotic GFP-RAW by wild type MC (C) and by Itga8-/- MC (D) after 4 hours of co-culture. Apoptotic GFP-RAW are depicted in green (P1), not phagocytosing MC in blue (P3), phagocytosing $\mathrm{MC}$ in purple dots (P4). 


\section{Cellular Physiology and Biochemistry}

calculated as the ratio of the number of phagocytosing cells to the total cell number, similar to $[28,38]$. In inhibition assays, the phagocytosis rate of matrixcoated beads by WT MC seeded on fibronectin was normalized to $100 \%$ as baseline level.

\section{Selective integrin blocking}

Blocking antibodies to $\alpha 6$ and $\alpha 2$ integrin chains (both BD Pharmingen, Heidelberg, Germany) were used at a concentration of $2 \mu \mathrm{g} / \mathrm{ml}, \alpha \mathrm{V} \beta 3$ integrin blocking RGD peptides and the negative peptide control (cRAD) (both from Bachem, Bubendorf, Switzerland) at a concentration of 5 and $50 \mu \mathrm{M}$, as described in [39]. MC were incubated with blocking antibodies or with blocking RGD peptides for 1 hour at $37^{\circ} \mathrm{C}$

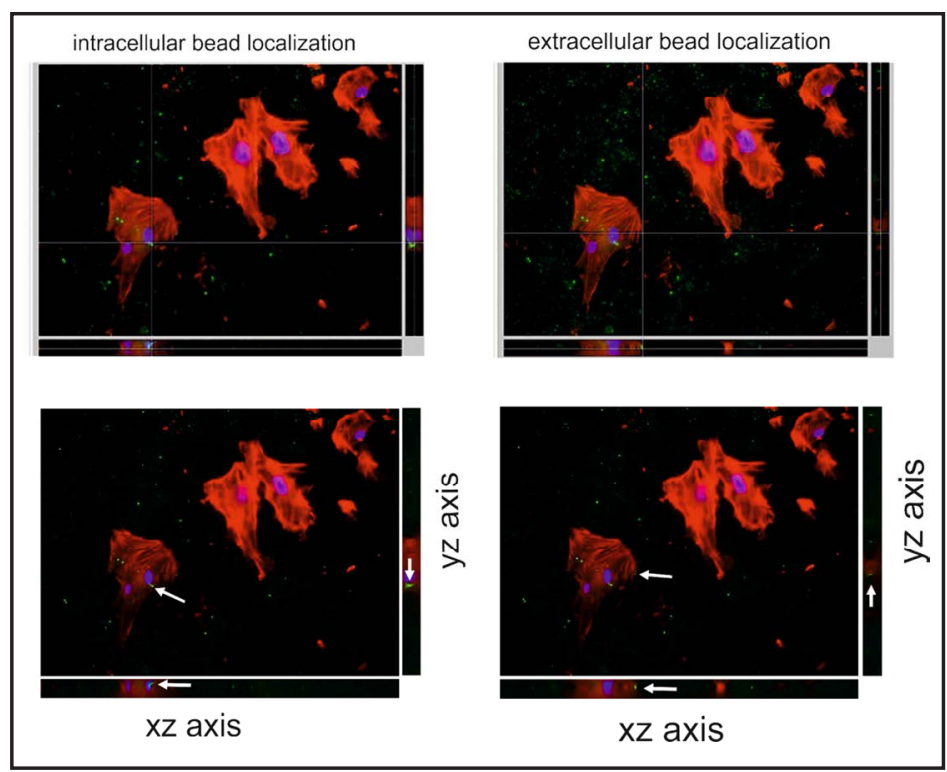

Fig. 3. Visualization of bead localization. Examples of fluorescence microscopic images with z-stacks to verify intracellular bead localization in wild type MC. Left: intracellular bead localization (white arrow). Right: extracellular bead localization (white arrow). Nuclei are stained with DaPi, actin filaments with rhodamine/phalloidin.

before starting phagocytosis assays.

\section{Inhibition of actin polymerization}

MC were either treated with medium containing Cytochalasin $\mathrm{D}(0.5,1.0$ and $10 \mu \mathrm{M})$ for 30 minutes to inhibit actin polymerization or treated with an equal amount of the solvent dimethylsulfoxide (DMSO) only, see Fig. 1D (similar as described [31, 40,41]). Then, latex beads were added to start phagocytosis, as described above.

\section{Inhibition of Rho GTPase-dependent actin remodeling}

ROCK inhibitor Y27632 (Calbiochem, La Jolla, CA, USA) is a selective inhibitor of the Rho-associated kinase p160 ROCK (an effector kinase of RhoA), NSC23766 (Abcam, Cambridge, UK) is an inhibitor of Rac1. Before starting phagocytosis assays with latex beads, as described above, MC were incubated with Y27632 at a concentration of $10 \mu \mathrm{M}$ for 15 minutes at $37^{\circ} \mathrm{C}$, as described in [42]. NSC23766 was used at two different concentrations $(10$ and $50 \mu \mathrm{M})$ for incubation of $\mathrm{MC}$ for 30 minutes at $37^{\circ} \mathrm{C}$, as described in [43].

\section{Silencing of Itga8 in rat $M C$}

Gene silencing of Itga8 was achieved by transfection of rat MC with Itga8 siRNA (si Itga8) according to the "fast protocol" from the HiPerFect Transfection Reagent Handbook (Qiagen, Hilden, Germany). MC were transfected in cell suspension with a final concentration of $5 \mathrm{nM}$ si Itga8 (sense: GAC CUC CUC AGG AUG AAA UdT dT, antisense: AUU UCA UCC UGA GGA GGU CdT dT, Qiagen) before seeding to allow silencing for 72 hours. A nonsilencing siRNA (si co) (sense: UUC UCC GAA CGU GUC ACG UdT dT, antisense: ACG UGA CAC GUU CGG AGA AdTdT, Qiagen) was used as control. To control for effective silencing, real-time PCR for Itga8 expression levels was performed, as described in [26]. Moreover, western blot analysis was used to confirm down regulation of Itga8 on protein level.

\section{Isolation of mRNA and Real-time PCR}

To evaluate mRNA expression levels of Itga8 and Acta2 ( $\alpha$-smooth muscle actin) after silencing of Itga8 with siRNA, total RNA was obtained from rat MC by extraction with RNeasy ${ }^{\circledR}$ Mini columns (Qiagen, Hilden, Germany). First-strand cDNA was synthesized with TaqMan reverse transcription reagents 


\section{Cellular Physiology Cell Physiol Biochem 2018;45:2161-2173 \begin{tabular}{ll|l} 
DOI: 10.1159/000488160 & Ond Biochemistry & $\begin{array}{l}\text { O 2018 The Author(s). Published by S. Karger AG, Basel } \\
\text { www.karger.com/cpb }\end{array}$
\end{tabular} \\ Marek et al.: Mesangial Itga8 and Phagocytosis}

(Applied Biosystems, Weiterstadt, Germany) using random hexamers as primers. Final RNA concentration in the reaction mixture was adjusted to $100 \mathrm{ng} / \mu \mathrm{L}$. Reactions without MultiScribe Reverse Transcriptase (Applied Biosystems) were used as negative controls for genomic DNA contamination. PCR was performed with an ABI PRISM 7000 Sequence Detector System and SYBR Green (Applied Biosystems) according to the manufacturer's instructions. The relative amount of the specific mRNA was normalized with respect to Rn18s. Primers were created with Primer3 Output program (http://biotools.umassmed.edu/ bioapps/primer3_www.cgi). Primer sequences (MWG Biotech, Ebersberg, Germany) used for Rn18s were forward 5'-TTGATTAAGTCCCTGCCCTTTGT-3', reverse 5'-CGATCCGAGGGCCTCACTA-3', for Itga8 forward 5'-TCCAAATCAGAAGCTCCAACAA-3', reverse 5'-CGCTCACGAAATTGCTGTCA-3' and for Acta2 forward 5'-TCCTGACCCTGAAGTATCCGATA-3', reverse 5'-GGTGCCAGATCTTTTCCATGTC-3'. All samples were run in triplicates.

\section{Detection of F-actin and Itga8 in cultured cells}

For F-actin staining, MC were seeded on glass 8-well chamber slides blocked with 2\% BSA. Cells were allowed to adhere for 24 hours. Then, adherent cells were rinsed three times with PBS and fixed in 4\% paraformaldehyde (PFA) for 10 minutes. Cells were permeabilized using 1\% Triton X-100 and nonspecific binding was blocked using 100\% FCS. F-actin was visualized with rhodamin/phalloidin from Molecular Probes (Leiden, The Netherlands). Cells were embedded in Tris-buffered Mowiol, pH 8.6 (Hoechst, Frankfurt, Germany). For staining of Itga 8 in HEK cells, Itga $8+/+$ HEK and co HEK were seeded on fibronectin $(10 \mu \mathrm{g} /$ $\mathrm{ml}$ ) coated 8-well chamber slides blocked with $2 \%$ BSA. Cells were allowed to adhere overnight. Then, cells were prefixed with $4 \%$ PFA $(0.3 \mathrm{ml} 4 \%$ PFA added to $0.5 \mathrm{ml}$ medium/well) for 2 minutes at room temperature, washed carefully with PBS and fixed with 4\% PFA for 20 minutes. After washing twice with PBS, cells were permeabilized using $0.2 \%$ Triton X-100/PBS. After rinsing twice with PBS, cells were stained with an Itga8 antibody (polyclonal goat anti-mouse/rat IgG, AF4076, R\&D Systems, Minneapolis, USA) 1:50 in PBS overnight at $4^{\circ} \mathrm{C}$. After washing three times with PBS, a cy ${ }^{\mathrm{TM}} 3$-conjugated donkey anti-goat IgG secondary antibody (Jackson ImmunoResearch Laboratories, Nr 705-166-147, West Grove, PA, USA) was applied 1:300 in PBS for 1 hour at $37^{\circ} \mathrm{C}$. Finally, after washing with PBS, chamber slides were embedded with Fluoromount ${ }^{\mathrm{TM}}$ (Sigma Aldrich).

\section{Western Blot Analysis}

Protein was isolated from MC with cell lysis buffer (50mM HEPES pH 7.4, 150mM NaCl, $1 \%$ Triton X-100, 1mM EDTA, Complete Protease-Inhibitor Cocktail (Roche, Mannheim) by incubating harvested cells on ice for 30 minutes with intermittent vortexing, followed by centrifugation for 10 minutes at 13, $000 \mathrm{rpm}$. Protein concentration of cell lysate supernatants was determined using a protein assay kit (Pierce, Rockford, IL). Protein samples containing $30 \mu \mathrm{g}-50 \mu \mathrm{g}$ total protein were denatured by boiling for five minutes and separated on an 8\% denaturing SDS-PAGE gel. After electrophoresis, the gels were electro blotted onto PVDF membranes (Pall Filtron, Karlstein, Germany), blocked with Roti-Block (Roth, Karlsruhe, Germany) for $\alpha$-smooth muscle actin (SMA), Itga8 and $\beta$-actin detection, or $5 \%$ low fat milk in TBS-T (Humana Milchunion eG, Herford, Germany) for $\beta$-tubulin detection, for 1 hour and incubated with the primary antibody overnight. A mouse monoclonal antibody to SMA (DAKO Diagnostika, Hamburg, Germany) was used at a dilution of 1:1000 in 1x Roti-Block. A goat anti-mouse antibody to Itga 8 (R\&D Systems) was used at a dilution of 1:1000 in 1x Roti-Block. As loading controls, a rabbit polyclonal antibody to $\beta$-tubulin (Abcam, Cambridge, UK) was used at a dilution of 1:5000 in 1\% FCS/PBS and a mouse monoclonal antibody to $\beta$-actin (Sigma Aldrich) was used at a dilution of 1:20, 000 in Roti-Block. Horseradish peroxidase-conjugated antimouse IgG antibody and anti-rabbit IgG antibody (Santa Cruz Biotechnology, Heidelberg, Germany), both diluted 1:10, 000 in TBS-T, and anti-goat IgG antibody (Santa Cruz Biotechnology), diluted 1:50, 000 in TBS-T were used as secondary antibodies, respectively. Immunoreactivity was visualized with a secondary horseradish peroxidase-conjugated IgG antibody, using the ECL system according to the manufacturer's instructions (Amersham, Braunschweig, Germany). Densitometric evaluation was performed using AIDA image analyzer 4.15 (Raytest, Berlin).

\section{Statistics}

A two-tailed student's t-test was used to test significance of differences between groups. A p-value of $<0.05$ was considered significant. Values are displayed as means \pm standard deviation. 


\section{Cellular Physiology Cell Physiol Biochem 2018;45:2161-2173

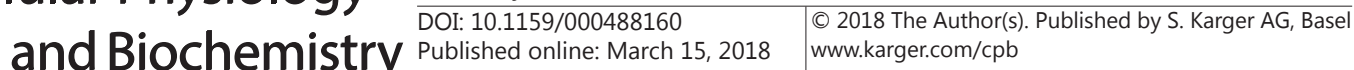 \\ Marek et al.: Mesangial Itga8 and Phagocytosis}

\section{Results}

\section{Phagocytosis of latex beads by $M C$}

The number of MC performing phagocytosis of extracellular matrix-coated beads was significantly higher in wild type MC compared to Itga8-/- MC (Fig. 4) with a higher affinity of both cell types to fibronectin-coated than collagen-coated beads (Fig. 4). 24 hours after incubation with fibronectincoated beads, phagocytosis was detected in nearly $80 \%$ of wild type MC, but only in about $45 \%$ of Itga8-/- MC. At the same time, nearly $40 \%$ of wild type MC but only 10\% of Itga8-/- MC internalized collagen-coated beads.

To gain more insight in the pathways involved in phagocytosis of wild type versus Itga8-/- MC, we performed inhibition assays for certain integrins and regulators of cytoskeletal organization.

Functional blocking of the RGD-binding $\alpha \mathrm{V}$ integrin, an integrin known to be mainly involved in phagocytosis in MC [20], resulted in a significant dose-dependent reduction of phagocytosis of fibronectin-coated beads in wild type MC (Fig. 5A), while there was only a moderate, yet insignificant reduction of phagocytosis in Itga8-/- MC (Fig. 5B).

Previous studies showed an increase in the

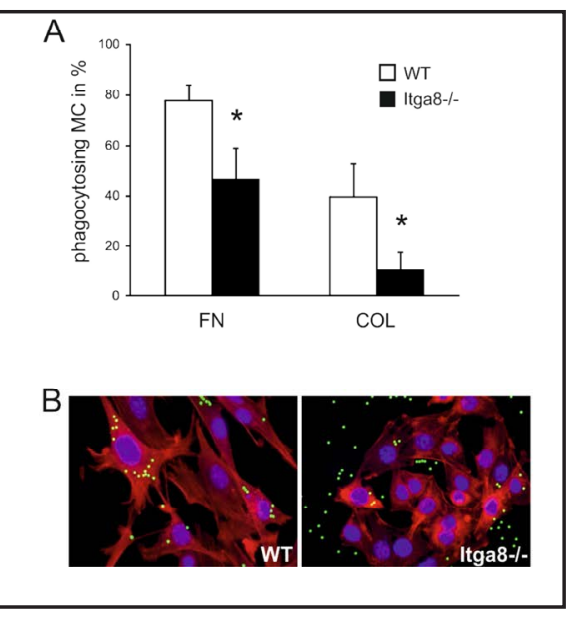

Fig. 4. Phagocytosis of matrix-coated beads. A, Comparison of the uptake of extracellular matrix-coated latex beads in $\alpha 8$ integrin-deficient (Itga8-/-) and in wild type (WT) mesangial cells (MC). B, exemplary photomicrographs of WT and Itga8-/- MC during phagocytic uptake of matrix-coated beads. Nuclei were stained with DaPi, actin filaments with rhodamine/ phalloidin. $\mathrm{FN}=$ Fibronectin, $\mathrm{COL}=$ Collagen I, N=3, * $=$ p $<0.05$ Itga8-/- versus WT MC.

expression of $\alpha 2$ and $\alpha 6$ integrins in Itga 8 /- MC [22]. Therefore, we hypothesized that these integrins might partly compensate the loss of Itga 8 for phagocytosis. The use of inhibitory antibodies to $\alpha 2$ and $\alpha 6$ integrins revealed a decreased rate of phagocytosis of fibronectin-coated latex beads in wild type MC to $88.9 \%$ after blocking of $\alpha 2$ integrin, to $85.5 \%$ after blocking of $\alpha 6$ integrin and to $78 \%$ after simultaneous blocking of both $\alpha 2$ and $\alpha 6$ integrin compared to untreated controls (Fig. 5C). In contrast, no significant reduction of phagocytosis after blocking $\alpha 2$ and $\alpha 6$ integrin was observed in Itga8-/$\mathrm{MC}$ arguing against a compensatory role for these integrins (Fig. 5D).

Inhibition of actin remodeling was achieved by ROCK and Rac1 inhibitors. ROCK inhibition showed a significant reduction of phagocytosis of fibronectincoated latex beads in wild type $\mathrm{MC}$, but not in Itga8-/- MC (Fig. 6A and B, respectively). Rac1 inhibition dose-dependently reduced phagocytosis of fibronectin-coated beads in wild type $\mathrm{MC}$, with the strongest effect at a concentration of $50 \mu \mathrm{M}$ (Fig. 6C). In Itga8-/$\mathrm{MC}$, no significant effect of the Rac1 inhibitor

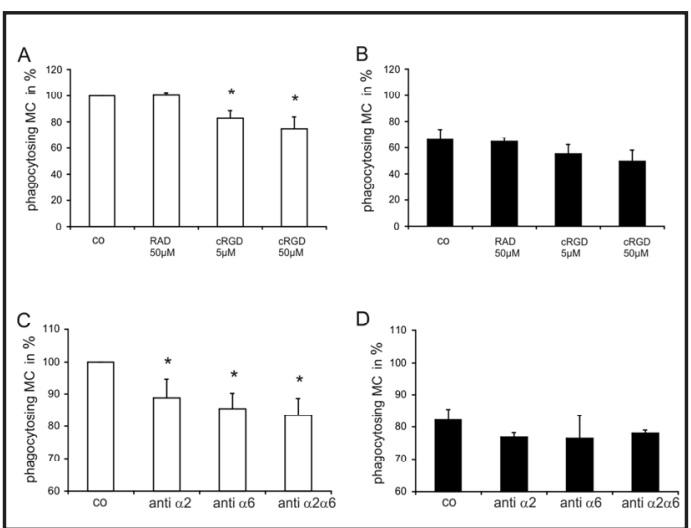

Fig. 5. Inhibition of integrin chains $(\alpha v, \alpha 2, \alpha 6)$ during phagocytosis. Inhibition of the uptake of fibronectin-coated beads in wild type (A) and $\alpha 8$ integrin-deficient (B) mesangial cells (MC) by cRGD. $\mathrm{RAD}=$ control non-blocking peptide, $\mathrm{CRGD}=\alpha \mathrm{V}$ integrin-blocking peptide. $\mathrm{N}=3,{ }^{*}=\mathrm{p}<0.05$ versus unstimulated control (co). Inhibition of phagocytosis of fibronectin-coated beads by $\alpha 2$ or $\alpha 6$ integrinblocking antibodies (anti $\alpha 2$, anti $\alpha 6$ ) and by both antibodies applied together (anti $\alpha 2 \alpha 6$ ) in wild type (C) and $\alpha 8$ integrin-deficient (D) mesangial cells (MC). $\mathrm{N}=3,{ }^{*}=\mathrm{p}<0.05$ versus unstimulated control (co). on phagocytosis was detected (Fig. 6D). 


\section{Cellular Physiology Cell Physiol Biochem 2018;45:2161-2173 \begin{tabular}{l|l|l} 
DOI: 10.1159/000488160 & a 2018 The Author(s). Published by S. Karger AG, Basel \\
www.karger.com/cpb
\end{tabular} \\ Marek et al.: Mesangial Itga8 and Phagocytosis}

Fig. 6. Inhibition of actin remodeling during phagocytosis. Inhibition of phagocytosis of fibronectin-coated beads by a ROCK inhibitor (ROCK-Inh) in wild type (A) and $\alpha 8$ integrindeficient (B) mesangial cells (MC). Inhibition of phagocytosis of fibronectin-coated beads by a RAC1 inhibitor (Rac1-Inh) in wild type (C) and $\alpha 8$ integrin-deficient (D) mesangial cells (MC). $\mathrm{N}=6$, $*=\mathrm{p}<0.05$ versus unstimulated control (co).

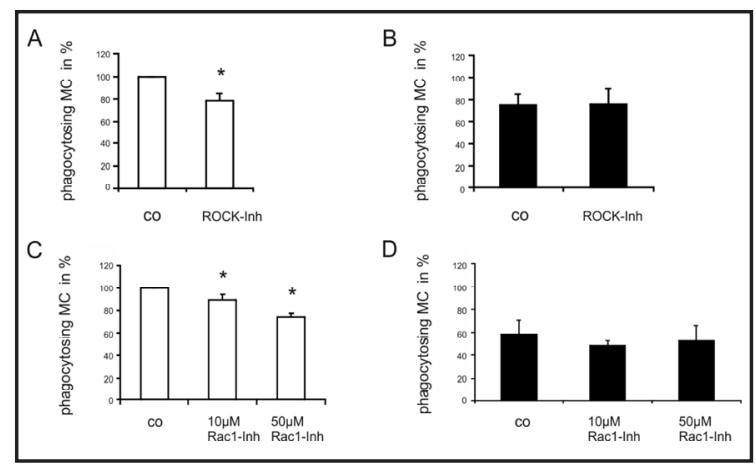

Fig. 7. Phagocytosis of fibronectin-coated latex beads in HEK cells. A, uptake of fibronectin-coated beads (green fluorescence) by Itga8-overexpressing HEK cells (Itga8+/+, $\mathrm{C}+\mathrm{E}$ ) and wildtype HEK cells (co, B, D+F) after 3 and 24 hours, exemplary photomicrographs representative for 3 similar independent experiments. ${ }^{*}=p<0.05$ Itga8 $+/+$ versus co. E, F, control staining of $\alpha 8$ integrin in Itga8+/+ (E) and co HEK cells (F).

Inhibition of actin polymerization resulted in a significant reduction of phagocytosing cells. Pretreatment with Cytochalasin D reduced the number of phagocytosing MC, both of the wild type and the Itga8-/- phenotype, in a dose dependent manner (Fig. 1D).

Phagocytosis of latex beads by HEK cells

After 3 hours of phagocytosis of fibronectincoated beads, Itga 8 overexpressing HEK cells (Itga8+/+ HEK) showed a higher phagocytosis rate $\quad(34.9 \%$ phagocytosing cells) compared to wild type HEK cells (co HEK, 12.1\% phagocytosing cells). After 24 hours, the phagocytosis rate was not significantly different in both cell types anymore $(91.2 \%$ in Itga8+/+ HEK cells versus $87.8 \%$ in co HEK, see Fig. 7).

\section{Phagocytosis of apoptotic RAW cells by $M C$}

Cisplatin was used to induce apoptosis in GFP-RAW. $50 \mu \mathrm{M}$ cisplatin induced an apoptotic rate of $82.8 \%$ compared to $4.6 \%$ in unstimulated controls (Fig. 8A). Phagocytosis of apoptotic RAW cells was significantly reduced in Itga8-/- MC compared to wild type $\mathrm{MC}$ after 2, 4 and 6 hours of coincubation. After 24

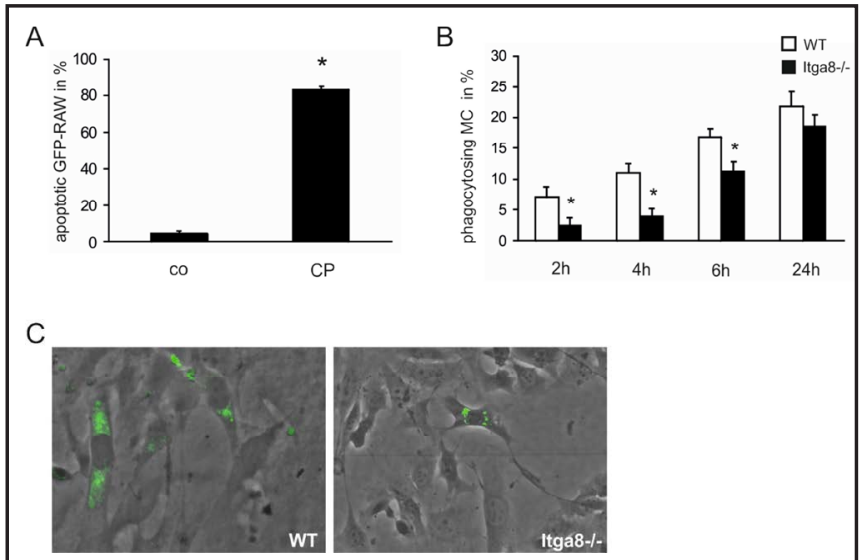

Fig. 8. Phagocytosis of GFP-labelled RAW cells (GFP-RAW). A, Induction of apoptosis in GFP-RAW by $50 \mu \mathrm{M}$ cisplatin (CP). $\mathrm{N}=3 .{ }^{*}=\mathrm{p}<0.05$ versus unstimulated control (co). B, Uptake of apoptotic GFP-RAW in wild type (WT) and $\alpha 8$ integrin-deficient (Itga8-/-) mesangial cells (MC). $\mathrm{N}=3,{ }^{*}=\mathrm{p}<0.05$ Itga8-/- versus WT MC. C, exemplary photomicrographs of MC phagocytosing apoptotic GFP-RAW after 6 hours. 


\section{Cellular Physiology Cell Physiol Biochem 2018;45:2161-2173 \begin{tabular}{l|l} 
DOI: 10.1159/000488160 & and Biochemistry \\
Published onlne:March 15, 2018 & $\begin{array}{l}\text { O } 2018 \text { The Author(s). Published by S. Karger AG, Basel } \\
\text { www.karger.com/cpb }\end{array}$
\end{tabular} \\ Marek et al.: Mesangial Itga8 and Phagocytosis}

Fig. 9. Phagocytosis of DiI-labelled apoptotic MC. A, Uptake of apoptotic DiI-stained wild type (WT) and $\alpha 8$ integrin deficient (Itga8-/-) mesangial cells (MC) by native MC after 4 and 24 hours. $\mathrm{N}=3, *=\mathrm{p}<0.05$ Itga8-/- versus WT. $\mathrm{B}$, exemplary photomicrographs of MC phagocytosing apoptotic MC after 4 hours.

hours, phagocytosis did not differ significantly in both cell types any more (Fig. 8B). Fig. 8C shows exemplary photomicrographs after 6 hours of coincubation.

Phagocytosis of apoptotic MC by MC

Apoptosis was induced in MC using $50 \mu \mathrm{M}$ cisplatin as described before [24]. Phagocytosis of apoptotic MC differed significantly after 4 hours with a higher rate of uptake in wild type MC (40.8\% versus $23.7 \%$ Itga8-/- MC). After 24 hours, the rate of phagocytosis of apoptotic MC by Itga8-/- MC and wild type MC was comparable (Fig. 9).

Changes in the actin cytoskeleton after loss of Itga8

Itga8-/- MC acquire a different cell shape compared to wild type MC (Fig. 10A). Stainings for F-actin revealed that typical stress fibers and the fibroblast-like phenotype of wild type $\mathrm{MC}$ are no longer present in Itga8-/- MC (Fig. 10A). Similar observations were made after a knockdown of Itga 8 using si RNA to Itga8, which also results in a change of the arrangement of actin filaments in the cell boundary close to the cell membrane and a more compact morphology (Fig. 10B). Moreover, like already described for Itga8-/- MC [22], in si Itga $8 \mathrm{MC} \alpha$-smooth muscle actin is downregulated after a transient knock down of Itga8 (Fig. 10C, D, E). Thus, underexpression of Itga8 results in profound changes in the cytoskeletal structure.

\section{Discussion}

Mesangial cells can serve as non-professional phagocytes, thereby supporting healing of the glomerular tuft after glomerulonephritis [1]. Itga 8 is an integrin which is specifically expressed on mesangial cells in the glomerulus [25]. Based on our in vivo findings of delayed glomerular regeneration after glomerulonephritis in Itga8deficient mice [24], phagocytosis of apoptotic
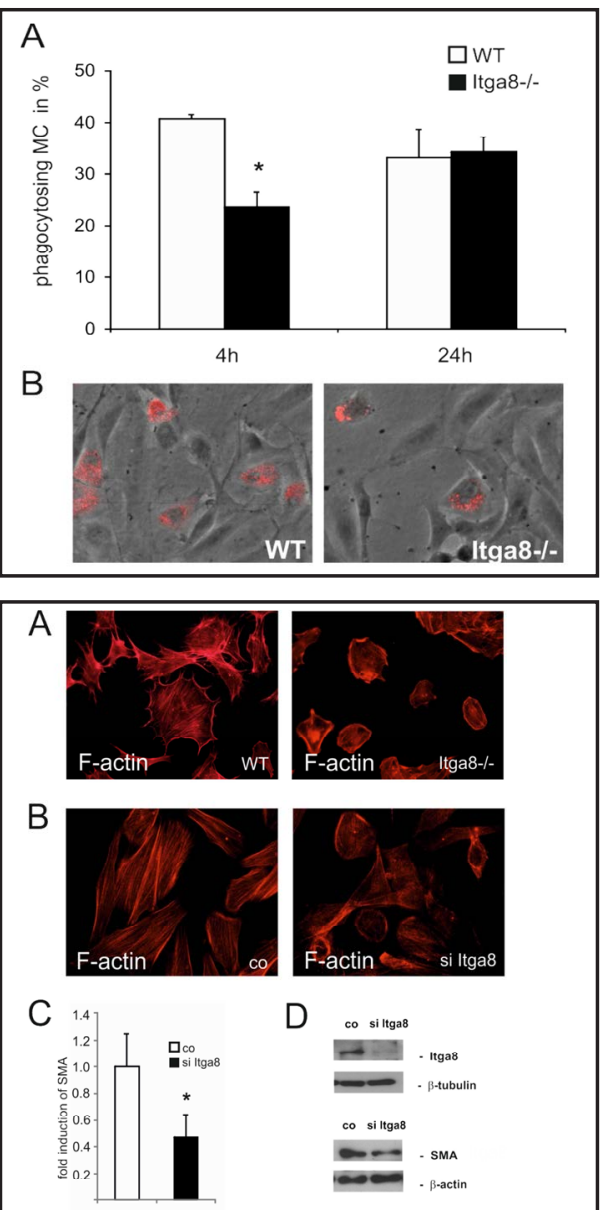

D so siltgas

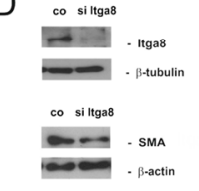

E

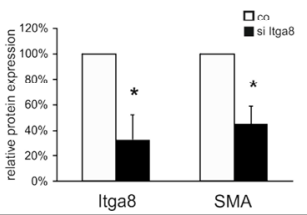

Fig. 10. Changes in the actin cytoskeleton after the loss of $\alpha 8$ integrin. A, F-actin staining in $\alpha 8$ integrin-deficient (Itga8-/-) and wild type (WT) mesangial cells (MC). B, F-actin staining after silencing of Itga8 in MC (si Itga8). C, $\alpha$-smooth muscle actin (SMA) mRNA expression in si Itga8 MC. $\mathrm{N}=3$. $*=\mathrm{p}<0.05$ versus non-silencing control (co). $D$, representative western blots for Itga8 and SMA after silencing of Itga 8 in MC (si Itga8), $\beta$-tubulin, $\beta$-actin= loading control. $\mathrm{E}$, statistical analysis after densitometric evaluation of western blots for Itga8 and SMA after silencing of Itga8 in MC (si Itga8). $\mathrm{N}=3$, $*=p<0.05$ versus control (co). cells and matrix components was analyzed in Itga8-deficient mesangial cells in vitro as a possible mechanism affecting the speed of tissue regeneration. In mesangial cells, the 
functional relevance of $\alpha \mathrm{V} \beta 3$ integrin as a mediator of phagocytosis was described by CortesHernandez et al [20].. The role of Itga8, however, for phagocytosis in glomerular regeneration or healing has not yet been elucidated. In our study, we investigated phagocytosis of matrix components by using matrix-coated beads and phagocytosis of apoptotic cells by using apoptotic GFP-transfected RAW cells or apoptotic DiI-stained mesangial cells in wild type and Itga8-deficient mesangial cells.

Our results show that the presence of Itga 8 facilitates phagocytosis of matrix components and apoptotic cells by mesangial cells. Thus, the expression of Itga 8 on mesangial cells could be especially beneficial after acute glomerulonephritis. Glomerulonephritis leads to an influx of inflammatory cells, mesangial cell hyperplasia and excessive deposition of extracellular matrix (fibrosis). Resolution of glomerulonephritis comprises apoptosis of surplus cells, which are removed via phagocytosis conducted by mesangial cells in addition to macrophages [1]. It is therefore conceivable that an ineffective mesangial phagocytosis, e.g. secondary to Itga8 deficiency, could result in a retardation of glomerular healing as seen in Itga8-deficient mice after induction of acute Habu nephritis [24].

The amount of phagocytosing cells was significantly reduced in Itga8-deficient compared to wild type mesangial cells. This was independent of the ingested particles. A deficiency in Itga8 led to reduced phagocytosis of apoptotic mesangial cells, apoptotic inflammatory cells and matrix components. Thus, Itga 8 seems to play an important role for phagocytosis by mesangial cells. However, there is still a considerable amount of Itga8-deficient mesangial cells capable of engulfing and ingesting particles, which implies that there are additional factors conveying phagocytosis by mesangial cells. The RGD-binding $\alpha V$ integrin is abundant on mesangial cells. This integrin is known to be critically involved in the phagocytosis of apoptotic cells by mesangial cells [20]. The inhibition of $\alpha \mathrm{V}$ integrin in Itga8-deficient cells, however, did not significantly reduce phagocytosis of coated beads by Itga8-deficient mesangial cells, arguing against a decisive contribution of $\alpha \mathrm{V}$ integrin to phagocytosis by Itga8-deficient mesangial cells. Previous studies have shown that Itga8-deficient mesangial cells express more $\alpha 2$ and $\alpha 6$ integrins than wild type mesangial cells [24, 44]. A contribution to collagen internalization was described for $\alpha 2 \beta 1$ integrin in fibroblasts [18]. Therefore, we analyzed the phagocytosis capacity of Itga8-deficient mesangial cells after blocking of $\alpha 2$ and $\alpha 6$ integrins. Although blocking of $\alpha 2$ and $\alpha 6$ integrins readily reduced the ingestion of matrix-coated beads by wild type mesangial cells, it had no effect on phagocytosis by Itga 8 deficient mesangial cells.

Moreover, the reduction of the rate of phagocytosis in mesangial cells lacking Itga 8 seemed to be independent from the matrix protein used for coating. Fibronectin is a ligand for Itga8, while collagen I is not, but ingestion of both matrix components was reduced in Itga8-deficient mesangial cells. This argues against an effect mediated by direct integrin receptor-ligand binding.

In line with this observation, phagocytosis by both wild type and Itga8-deficient mesangial cells is strongly dependent on a functional cytoskeleton. Actin rearrangement is a crucial prerequisite for the uptake of particles and apoptotic cells by phagocytes [45]. Thus, inhibition of actin cytoskeleton rearrangement results in inhibition of phagocytosis. As important regulators of actin rearrangement Rho GTPases are effective modulators of phagocytosis in various cell types [45]. Rac1 is a Rho GTPase, which is involved in cell motility and other cell functions by controlling the function of lamellipodia. Activation of Rac1 is important for the engulfment of apoptotic cells by the phagocytes' lamellipodia [46]. Similarly, the Rho-associated protein kinase (ROCK) is able to support phagocytosis as described in macrophages [47]. In accordance with these data, inhibition of Rac1 or ROCK attenuated phagocytosis of wild type mesangial cells, while in Itga8-deficient cells inhibition of Rac1 or ROCK was less effective on phagocytosis. This further argues for Itga8-mediated differences in the organization of the cytoskeleton in wild type and Itga8-deficient mesangial cells [22]. Phagocytosis by Itga8-deficient mesangial cells is less effective, but is also less dependent on the ability of the cell to perform actin rearrangements. While wild type mesangial cells show the typical mesenchymal phenotype, Itga8-deficient mesangial cells are characterized by a

\section{KARGER}




\section{Cellular Physiology Cell Physiol Biochem 2018;45:2161-2173 \begin{tabular}{l|l} 
and Biochemistry Published onlıne: March 15, 2018 & $\begin{array}{l}\text { (c) } 2018 \text { The Author(s). Published by S. Karger AG, Basel } \\
\text { www.karger.com/cpb }\end{array}$
\end{tabular}

more epithelial rather than a mesenchymal phenotype [22]. This observation was also made in mesangial cells with a transient knock-down of Itga 8 which similarly results in a loss of the fibroblast-like phenotype with a different, more compact arrangement of actin filaments close to the cell membrane. In mesangial cells with a transient knock-down of Itga8, however, the actin cytoskeleton changes are somewhat milder than in mesangial cells with a genetic itga 8 knock-out, which might be due to an incomplete blockade of Itga 8 expression. Thus, the process of phagocytosis might be somewhat different from wild type mesangial cells. In mammary epithelial cells for instance, E-cadherin seems to contribute to phagocytosis [48]. This is in contrast to the phagocytosis in mesenchymal cells, where E-cadherin is commonly not found. Moreover, changes of the cell shape including cell rounding can result in reduced phagocytosis capacity as described in macrophages [49-51].

\section{Conclusion}

Taken together, we show that a loss of Itga 8 leads to a reduced phagocytosis capacity of matrix coated beads and of apoptotic cells by mesangial cells. Thus, Itga 8 seems to contribute to an effective mesangial cell phagocytosis in vitro. This does not seem to be due to a direct involvement of Itga8 in the process of phagocytosis. Instead, reduced phagocytosis might arise from a change in cytoskeletal organization, secondary to the lack of Itga8. We speculate that the attenuation of phagocytosis as a consequence of an underexpression of Itga8 could contribute to the observed retardation in glomerular regeneration after renal damage in a model of mesangioproliferative glomerulonephritis in Itga8-deficient mice. However, our study is limited in that the significance of our in vitro findings for the in vivo situation remains to be shown.

\section{Acknowledgements}

This study was supported by a grant from the ELAN fund, University Hospital of Erlangen and an educational grant from the Interdisciplinary Center for Clinical Research of the Faculty of Medicine of the Friedrich-Alexander University Erlangen-Nürnberg to IM and by a grant from the Deutsche Forschungsgemeinschaft SFB 423 (A2) to AH. The authors thank Dr. Ulrich Muller (Scripps Institute, LaJolla, USA) for providing the Itga8-deficient mouse strain and Prof. Ben Wielockx and Dr. Joanna Kalucka (Dresden, Germany) for providing the stably GFP-transfected RAW cells. The authors thank Miroslava Kupraszewicz-Hutzler for technical assistance.

We acknowledge support by Deutsche Forschungsgemeinschaft and FriedrichAlexander-Universität Erlangen-Nürnberg (FAU) within the funding programme Open Access Publishing.

\section{Disclosure Statement}

The authors declare that they have no competing interests.

\section{References}

$>1$ Watson S, Cailhier JF, Hughes J, Savill J: Apoptosis and glomerulonephritis. Curr Dir Autoimmun 2006;9:188-204.

2 Sayedyahossein S, Dagnino L: Integrins and small GTPases as modulators of phagocytosis. Int Rev Cell Mol Biol 2013;302:321-354.

-3 Goodridge HS, Underhill DM, Touret N: Mechanisms of Fc receptor and dectin-1 activation for phagocytosis. Traffic 2012;13:1062-1071.

4 Flannagan RS, Jaumouille V, Grinstein S: The cell biology of phagocytosis. Ann Rev Pathol 2012;7:61-98. 


\section{Cellular Physiology Cell Physiol Biochem 2018;45:2161-2173 \begin{tabular}{l|l} 
and Biochemistry Published onlIne: March 15, 2018 & $\begin{array}{l}\text { (c) } 2018 \text { The Author(s). Published by S. Karger AG, Basel } \\
\text { www.karger.com/cpb }\end{array}$
\end{tabular}}

Marek et al.: Mesangial Itga8 and Phagocytosis

5 Baker AJ, Mooney A, Hughes J, Lombardi D, Johnson RJ, Savill J: Mesangial cell apoptosis: the major mechanism for resolution of glomerular hypercellularity in experimental mesangial proliferative nephritis. J Clin Invest 1994;94:2105-2116.

6 Krieser RJ, White K: Engulfment mechanism of apoptotic cells. Curr Opin Cell Biol 2002;14:734-738.

7 Underhill DM, Ozinsky A: Phagocytosis of microbes: complexity in action. Ann Rev Immunol 2002;20:825-852.

8 Lauber K, Blumenthal SG, Waibel M, Wesselborg S: Clearance of apoptotic cells: getting rid of the corpses. Mol Cell 2004;14:277-287.

-9 Hoppe AD, Swanson JA: Cdc42, Rac1, and Rac2 display distinct patterns of activation during phagocytosis. Mol Biol Cell 2004;15:3509-3519.

$\checkmark 10$ Dupuy AG, Caron E: Integrin-dependent phagocytosis: spreading from microadhesion to new concepts. J Cell Sci 2008;121:1773-1783.

11 Sayedyahossein S, Nini L, Irvine TS, Dagnino L: Essential role of integrin-linked kinase in regulation of phagocytosis in keratinocytes. FASEB J 2012;26:4218-4229.

12 Olazabal IM, Caron E, May RC, Schilling K, Knecht DA, Machesky LM: Rho-kinase and myosin-II control phagocytic cup formation during CR, but not FcgammaR, phagocytosis. Curr Biol 2002;12:1413-1418.

13 Albert ML, Kim JI, Birge RB: alphavbeta5 integrin recruits the CrkII-Dock180-rac1 complex for phagocytosis of apoptotic cells. Nat Cell Biol 2000;2:899-905.

-14 Mao Y, Finnemann SC: Essential diurnal Rac1 activation during retinal phagocytosis requires alphavbeta5 integrin but not tyrosine kinases focal adhesion kinase or Mer tyrosine kinase. Mol Biol Cell 2012;23:11041114 .

-15 Gagen D, Filla MS, Clark R, Liton P, Peters DM: Activated alphavbeta3 integrin regulates alphavbeta5 integrin-mediated phagocytosis in trabecular meshwork cells. Invest Ophthalmol Vis Sci 2013;54:5000-5011.

-16 Coopman PJ, Thomas DM, Gehlsen KR, Mueller SC: Integrin alpha 3 beta 1 participates in the phagocytosis of extracellular matrix molecules by human breast cancer cells. Mol Biol Cell 1996;7:1789-1804.

17 Koenigsknecht J, Landreth G: Microglial phagocytosis of fibrillar beta-amyloid through a beta1 integrindependent mechanism. J Neurosci 2004;24:9838-9846.

-18 Arora PD, Marignani PA, McCulloch CA: Collagen phagocytosis is regulated by the guanine nucleotide exchange factor Vav2 Am J Physiol Cell Physiol 2008;295:C130-137.

19 Arora PD, Manolson MF, Downey GP, Sodek J, McCulloch CA: A novel model system for characterization of phagosomal maturation, acidification, and intracellular collagen degradation in fibroblasts. J Biol Chem 2000;275:35432-35441.

20 Cortes-Hernandez J, Fossati-Jimack L, Carugati A, Potter PK, Walport MJ, Cook HT, Botto M: Murine glomerular mesangial cell uptake of apoptotic cells is inefficient and involves serum-mediated but complement-independent mechanisms. Clin Exp Immunol 2002;130:459-466.

-21 Hughes J, Liu Y, Van Damme J, Savill J: Human glomerular mesangial cell phagocytosis of apoptotic neutrophils: mediation by a novel CD36-independent vitronectin receptor/thrombospondin recognition mechanism that is uncoupled from chemokine secretion. J Immunol 1997;158:4389-4397.

-22 Marek I, Volkert G, Jahn A, Fahlbusch F, Zurn C, Ozcan Z, Goppelt-Struebe M, Hilgers KF, Rascher W, Hartner A: Lack of alpha8 integrin leads to morphological changes in renal mesangial cells, but not in vascular smooth muscle cells. BMC Cell Biol 2010;11:102.

23 Bieritz B, Spessotto P, Colombatti A, Jahn A, Prols F, Hartner A: Role of alpha8 integrin in mesangial cell adhesion, migration, and proliferation. Kidney Int 2003;64:119-127.

24 Hartner A, Marek I, Cordasic N, Haas C, Schocklmann H, Hulsmann-Volkert G, Plasa I, Rascher W, Hilgers KF, Amann K: Glomerular regeneration is delayed in nephritic alpha 8-integrin-deficient mice: contribution of alpha 8-integrin to the regulation of mesangial cell apoptosis. Am J Nephrol 2008;28:168-178.

25 Hartner A, Schocklmann H, Prols F, Muller U, Sterzel RB: Alpha8 integrin in glomerular mesangial cells and in experimental glomerulonephritis. Kidney Int 1999;56:1468-1480.

-26 Volkert G, Jahn A, Dinkel C, Fahlbusch F, Zurn C, Hilgers KF, Rascher W, Hartner A, Marek I: Contribution of the alpha8 integrin chain to the expression of extracellular matrix components. Cell Commun Adhes 2014;21:89-98.

-27 Mamlouk S, Kalucka J, Singh RP, Franke K, Muschter A, Langer A, Jakob C, Gassmann M, Baretton GB, Wielockx B: Loss of prolyl hydroxylase-2 in myeloid cells and T-lymphocytes impairs tumor development. Int J Cancer 2014;134:849-858. 


\section{Cellular Physiology Cell Physiol Biochem 2018;45:2161-2173

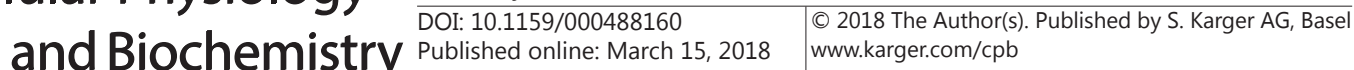

Marek et al.: Mesangial Itga8 and Phagocytosis

28 McCulloch CA, Knowles GC: Deficiencies in collagen phagocytosis by human fibroblasts in vitro: a mechanism for fibrosis? J Cell Physiol 1993;155:461-471.

29 Knowles GC, McKeown M, Sodek J, McCulloch CA: Mechanism of collagen phagocytosis by human gingival fibroblasts: importance of collagen structure in cell recognition and internalization. J Cell Sci 1991;98:551-558.

-30 van der Pauw MT, Van den Bos T, Everts V, Beertsen W: Phagocytosis of fibronectin and collagens type I, III, and $V$ by human gingival and periodontal ligament fibroblasts in vitro. J Periodontol 2001;72:1340-1347.

-31 Segal G, Lee W, Arora PD, McKee M, Downey G, McCulloch CA: Involvement of actin filaments and integrins in the binding step in collagen phagocytosis by human fibroblasts. J Cell Sci 2001;114:119-129.

-32 Cosio FG, Sedmak DD, Nahman NS, Jr.: Cellular receptors for matrix proteins in normal human kidney and human mesangial cells. Kidney Int 1990;38:886-895.

33 Blystone SD, Graham IL, Lindberg FP, Brown EJ: Integrin alpha v beta 3 differentially regulates adhesive and phagocytic functions of the fibronectin receptor alpha 5 beta 1 J Cell Biol 1994;127:1129-1137.

-34 Zhao MW, Jin ML, He S, Spee C, Ryan SJ, Hinton DR: A distinct integrin-mediated phagocytic pathway for extracellular matrix remodeling by RPE cells. Invest Ophthalmol Vis Sci 1999;40:2713-2723.

-35 McKeown M, Knowles G, McCulloch CA: Role of the cellular attachment domain of fibronectin in the phagocytosis of beads by human gingival fibroblasts in vitro. Cell Tissue Res 1990;262:523-530.

36 Gu BJ, Saunders BM, Jursik C, Wiley JS: The P2X7-nonmuscle myosin membrane complex regulates phagocytosis of nonopsonized particles and bacteria by a pathway attenuated by extracellular ATP. Blood 2010;115:1621-1631.

37 Gu BJ, Saunders BM, Petrou S, Wiley JS: P2X(7) is a scavenger receptor for apoptotic cells in the absence of its ligand, extracellular ATP. J Immunol 2011;187:2365-2375.

-38 Savill J, Smith J, Sarraf C, Ren Y, Abbott F, Rees A: Glomerular mesangial cells and inflammatory macrophages ingest neutrophils undergoing apoptosis. Kidney Int 1992;42:924-936.

39 Amann K, Haas CS, Schussler J, Daniel C, Hartner A, Schocklmann HO: Beneficial effects of integrin alphavbeta3-blocking RGD peptides in early but not late phase of experimental glomerulonephritis. Nephrol Dial Transplant 2012;27:1755-1768.

-40 Takahashi N, Kobayashi M, Takaki T, Takano K, Miyata M, Okamatsu Y, Hasegawa K, Nishihara T, Yamamoto M: Actinobacillus actinomycetemcomitans lipopolysaccharide stimulates collagen phagocytosis by human gingival fibroblasts. Oral Microbiol Immunol 2008;23:259-264.

41 Tiwari V, Shukla D: Nonprofessional phagocytosis can facilitate herpesvirus entry into ocular cells. Clin Dev Immunol 2012;2012:651691.

42 Rojas AM, Fuentes G, Rausell A, Valencia A: The Ras protein superfamily: evolutionary tree and role of conserved amino acids. J Cell Biol 2012;196:189-201.

43 Levay M, Krobert KA, Wittig K, Voigt N, Bermudez M, Wolber G, Dobrev D, Levy FO, Wieland T: NSC23766, a widely used inhibitor of Rac1 activation, additionally acts as a competitive antagonist at muscarinic acetylcholine receptors. J Pharmacol Exp Therapeut 2013;347:69-79.

-44 Haas CS, Amann K, Schittny J, Blaser B, Muller U, Hartner A: Glomerular and renal vascular structural changes in alpha8 integrin-deficient mice. J Am Soc Nephrol 2003;14:2288-2296.

45 Mao Y, Finnemann SC: Regulation of phagocytosis by Rho GTPases. Small GTPases 2015;6:89-99.

46 Nakaya M, Kitano M, Matsuda M, Nagata S: Spatiotemporal activation of Rac1 for engulfment of apoptotic cells. Proc Nat Acad Sci USA 2008;105:9198-9203.

47 Liu Y, Tejpal N, You J, Li XC, Ghobrial RM, Kloc M: ROCK inhibition impedes macrophage polarity and functions. Cell Immunol 2016;300:54-62.

48 Fornetti J, Flanders KC, Henson PM, Tan AC, Borges VF, Schedin P: Mammary epithelial cell phagocytosis downstream of TGF-beta3 is characterized by adherens junction reorganization. Cell Death Diff 2016;23:185-196.

49 Akei H, Whitsett JA, Buroker M, Ninomiya T, Tatsumi H, Weaver TE, Ikegami M: Surface tension influences cell shape and phagocytosis in alveolar macrophages. Am J Physiol Lung Cell Mol Physiol 2006;291:L572-579.

50 Haussler S, Rohde M, von Neuhoff N, Nimtz M, Steinmetz I: Structural and functional cellular changes induced by Burkholderia pseudomallei rhamnolipid. Infect Immun 2003;71:2970-2975.

-51 Rossi AG, McCutcheon JC, Roy N, Chilvers ER, Haslett C, Dransfield I: Regulation of macrophage phagocytosis of apoptotic cells by cAMP. J Immunol 1998;160:3562-3568. 